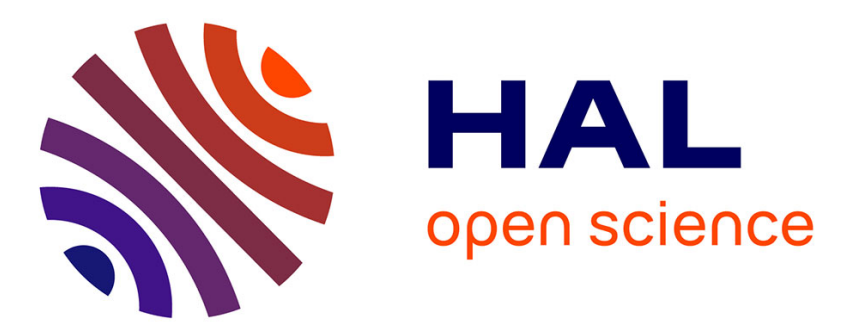

\title{
Characterization of a Dinuclear Copper(II) Complex and Its Fleeting Mixed-Valent Copper(II)/Copper(III) Counterpart
}

Amélie Kochem, Federica Gennarini, Mehdi Yemloul, Maylis Orio, Nicolas Le Poul, Eric Rivière, Michel Giorgi, Bruno Faure, Yves Le Mest, Marius Réglier, et al.

\section{To cite this version:}

Amélie Kochem, Federica Gennarini, Mehdi Yemloul, Maylis Orio, Nicolas Le Poul, et al.. Characterization of a Dinuclear Copper(II) Complex and Its Fleeting Mixed-Valent Copper(II)/Copper(III) Counterpart. ChemPlusChem, 2017, 82 (4), pp.615 - 624. 10.1002/cplu.201600636 . hal-01624533

\section{HAL Id: hal-01624533 \\ https://hal.univ-brest.fr/hal-01624533}

Submitted on 16 Dec 2021

HAL is a multi-disciplinary open access archive for the deposit and dissemination of scientific research documents, whether they are published or not. The documents may come from teaching and research institutions in France or abroad, or from public or private research centers.
L'archive ouverte pluridisciplinaire HAL, est destinée au dépôt et à la diffusion de documents scientifiques de niveau recherche, publiés ou non, émanant des établissements d'enseignement et de recherche français ou étrangers, des laboratoires publics ou privés. 


\title{
Characterization of a butterfly flapping dinuclear copper(II) complex and its fleeting mixed-valent $\mathrm{Cu}(\mathrm{II}) \mathrm{Cu}(\mathrm{III})$ counterpart.
}

\author{
Amélie Kochem, ${ }^{*[a]}$ Federica Gennarini, ${ }^{[b]}$ Mehdi Yemloul, ${ }^{[a]}$ Maylis Orio, ${ }^{[a]}$ Nicolas Le Poul, ${ }^{[b]}$ Eric \\ Rivière ${ }^{[\mathrm{c}]}$ Michel Giorgi, ${ }^{[\mathrm{d}]}$ Bruno Faure ${ }^{[\mathrm{a}]}$ Yves Le Mest,${ }^{[\mathrm{b}]}$ Marius Réglier ${ }^{[\mathrm{a}]}$ and A. Jalila Simaan ${ }^{[\mathrm{a}] *}$
}

Dedication: In memory of Professor T. Silviu Balaban

\begin{abstract}
In this study, we report on the synthesis of a dinuclear copper(II) complex supported by 1,3-diamino-2-propanol based tetra-amide ligand. Structural properties in the solid state and in solution, using X-Ray diffraction analysis and NMR spectroscopy respectively, have evidenced a highly flexible complex that can display several conformations leading to the image of a wing-tipped butterfly. The complex was fully characterized and the redox properties were investigated. Room-temperature spectroelectrochemistry was used to monitor the formation of a metastable monooxidized product that displays an absorption band centered at $463 \mathrm{~nm}$. Electronic Paramagnetic Resonance investigation of the low-temperature chemically-generated monooxidized product reveals the presence of an intermediate described as a mixed-valent $\mathrm{Cu}(\mathrm{II}) \mathrm{Cu}(\mathrm{III})$ species, model of the possible highly oxidizing intermediate in particulate Methane Monooxygenase.
\end{abstract}

energy source for the synthesis of the life required molecules. MMOs exist as soluble and particulate forms. ${ }^{[3]}$ The soluble form (sMMO) contains a diiron active site that achieves methane oxidation thanks to high-valent dinuclear bis $(\mu-0 \times 0) \mathrm{Fe}^{\mathrm{IV}} \mathrm{Fe}^{\mathrm{IV}}$ intermediate. ${ }^{[4,5]}$ The particulate form ( $\left.p M M O\right)$ is a membranebound enzyme that uses copper as metallic cofactor and which structure and mechanism is far less understood than that of the iron-containing SMMO. ${ }^{[6]} \mathrm{X}$-ray crystallographic studies have shown that $p M M O$ possesses several metal-binding sites ${ }^{[7,8,9]}$ Due to moderate crystallographic resolution and low copper binding stoichiometry, the exact nature of pMMO's active site is still controversy. ${ }^{[10,11]}$ However, recent studies suggest that methane oxidation is achieved at a dinuclear copper center. ${ }^{[12,13]}$ This active site was modeled as two copper ions located at short $\mathrm{Cu}-\mathrm{Cu}$ distance $(2.5-2.7 \AA)$ with one $\mathrm{Cu}$ ion bound by two histidine imidazoles and the other $\mathrm{Cu}$ bound by an imidazole and the amino group of the $\mathrm{N}$-terminal histidine in a coordination motif named "histidine-brace" (Figure 1).

\section{Introduction}

In a time when our society needs to diversify its energy sources, the development of catalysts that can convert the greenhouse gas methane into methanol as alternative for traditional fuels is of major interest. ${ }^{[1]}$ Currently, industrial methanol production is accomplished by steam reforming of methane, which requires high temperatures and pressures. Thus, new processes for efficient methane oxidation into methanol at low temperatures need to be developed. ${ }^{[2]}$ However, methane has the strongest $\mathrm{C}-\mathrm{H}$ bond of any hydrocarbon $(\mathrm{BDE}=104 \mathrm{kcal}$ $\mathrm{mol}^{-1}$ ) and its oxidation under mild conditions represents a major challenge in modern chemistry. On the other hand, in Nature, methane monooxygenases (MMOs) accomplish the conversion of methane into methanol at ambient temperature and atmospheric pressure, allowing the harnessing of methane as an

[a] Dr. A. Kochem, Dr. M. Yemloul, Dr. M. Orio, Dr. B. Faure, Dr. M. Réglier, Dr. A. J. Simaan

Aix Marseille Univ, CNRS, Centrale Marseille, iSm2, Marseille,

France

E-mail: amelie.kochem@hotmail.fr; jalila.simaan@univ-amu.fr

[b] F. Gennarini, Dr. N. Le Poul, Dr. Y. Le Mest

Université de Bretagne occidentale, CEMCA, UMR CNRS 6521 Brest, France

[c] Dr. E. Rivière

Institut de Chimie Moléculaire et des Matériaux d'Orsay, Univ Paris Sud, Université Paris-Saclay, CNRS, Orsay, France

[d] Dr. M. Giorgi

Aix Marseille Univ, CNRS, Spectropole FR1739, Marseille, France

Supporting information for this article is given via a link at the end of the document.

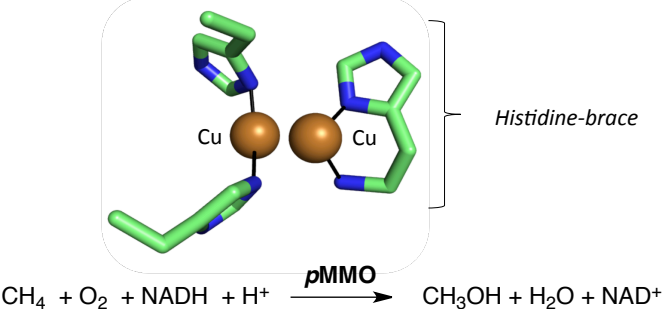

Figure 1. Structure of the dicopper active site of pMMO from Methylococcus capsulatus (Bath) and reaction catalyzed by $\mathrm{pMMO}$.

The mechanism and $\mathrm{Cu}_{2} / \mathrm{O}_{2}$ active species in methane oxidation are still debated and different types of intermediates have been postulated as possible active species (Scheme 1). ${ }^{[14]}$ In heterogeneous catalysis, Cu-loaded zeolites (Cu-ZSM-5) were shown to be able to produce methanol from methane at relatively low temperature $\left(\sim 100^{\circ} \mathrm{C}\right)$ with high selectivity through the formation of highly reactive $(\mu-0 x))_{C u}{ }_{2} \quad\left(\mathrm{Cu}_{2} \mathrm{O}\right)$ intermediates, making these species relevant for $p \mathrm{MMO}$ catalytic cycle. ${ }^{[15]}$ Synthetic $\mathrm{Cu}_{2} \mathrm{O}$ species have been described, but their ability to perform strong $\mathrm{C}-\mathrm{H}$ bond oxidation has not yet been established. ${ }^{[16]}$ Recently, theoretical calculations have shown that the dicopper site of $p \mathrm{MMO}$ can accommodate a $\left(\mu-\eta^{2}: \eta^{2}-\right.$ peroxo)Cu${ }_{2}$ species, similar to that found in tyrosinase or hemocyanin. ${ }^{[17]}$ Oxo-bridged high-valent bis( $\mu$-oxo $) \mathrm{Cu} \mathrm{III}_{2}$ species are able to perform various oxidation reactions, and have also been suggested as intermediates which may form during $p M M O$ catalysis. ${ }^{[18]}$ Stack and coworkers have shown that primary amine ligation reminiscent of the 'histidine brace' motif, provided greater stabilization to the bis( $\mu-0 \times 0) \mathrm{Cu}^{\mathrm{II}} 2$ intermediates without attenuation of their oxidizing power. ${ }^{[19]}$ 
Finally, using computational analysis, Yoshizawa and coworkers have suggested that mixed-valent $\mathrm{Cu}^{\prime \prime} \mathrm{Cu}^{\text {III }}$ species such as bis( $\mu$-oxo)Cu" Cu'll or $\left(\mu\right.$-oxo)( $\mu$-hydroxo)Cu ${ }^{\prime \prime} \mathrm{Cu}^{\prime \prime \prime}$ species are more reactive towards $\mathrm{C}-\mathrm{H}$ bonds than the bis $(\mu-o x 0) \mathrm{Cu}_{2}{ }_{2}$ species. ${ }^{[20,21,22]}$ Their newer calculations have suggested that methane oxidation in pMMO could be promoted by $(\mu-0 \times 0)(\mu-$ hydroxo) $\mathrm{Cu}^{\prime \prime} \mathrm{Cu}^{\text {III }}$ species that could arise from bis( $\mu$-oxo $) \mathrm{Cu}^{\text {III }}$ after one electron reduction followed by a proton transfer from a nearby tyrosine residue. ${ }^{[22]}$

$$
\begin{aligned}
& \mathrm{Cu}^{11}-\mathrm{O}-\mathrm{Cu} \\
& \mathrm{Cull}^{\prime \prime}-\mathrm{O}-\mathrm{O}-\mathrm{Cu} \\
& \mathrm{Cu}^{111}-\mathrm{O}-\mathrm{O}-\mathrm{Cu}^{\mathrm{III}} \\
& (\mu-\mathrm{oxo}) \mathrm{Cu}_{2}{ }_{2}\left(\mathrm{Cu}_{2} \mathrm{O}\right) \\
& \left(\mu-\eta^{2}-\eta^{2}-\text { peroxo }\right) \mathrm{Cu}_{2}{ }_{2} \\
& \text { bis( }(\mu-0 \times 0) C^{\prime \prime \prime \prime}{ }_{2} \\
& \mathrm{Cu}^{\prime \prime}-\mathrm{O}-\mathrm{Cu}^{\prime \prime \prime}
\end{aligned}
$$

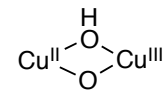

Scheme 1. Possible dicopper intermediates for methane oxidation at $p M M O$ active site.

To the best of our knowledge, only two examples of synthetic mixed-valent $\mathrm{Cu}^{\prime \prime} \mathrm{Cu}^{\prime \prime \prime}$ species have been reported. ${ }^{[23,24]}$ The group of Tolman has reported on the characterization of a hydroxo-bridged mixed-valent $\mathrm{Cu}^{\prime \prime} \mathrm{Cu}^{\text {III }}$ complex with a tetraanionic macrocyclic ligand containing two pyridine(dicarboxamide) moieties. This intermediate was able to perform $\mathrm{C}-\mathrm{H}$ bond activation of dihydroanthracene. ${ }^{[23]}$ Recently, using a naphtyridyl based ligand, Belle and coworkers have generated a bis(hydroxo) bridged mixed-valent $\mathrm{Cu}^{\prime \prime} \mathrm{Cu}^{\prime \prime \prime}$ species. ${ }^{[24]}$ Since only two examples have been reported, study of such mixed-valent complexes is of current interest in order to get deeper insight into their structure-function relationships. In the present study, we report on the synthesis and characterization of a dinuclear copper complex based on a polydentate amide-containing ligand $\mathrm{H}_{5} \mathrm{~L}$ (Scheme 2).

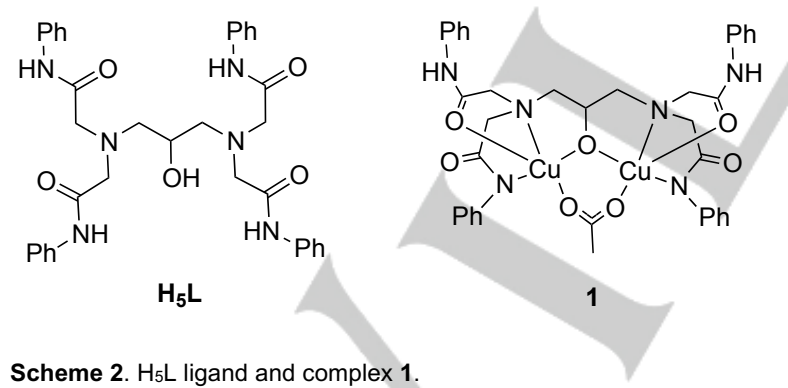

The choice of this ligand was driven by several features: (i) this kind of ligand is well known to accommodate two copper centers in close vicinity thanks to an alkoxo-bridging group ${ }^{[25]}$ (ii) the coordination mode of this ligand should allow the incorporation of an exogenous bridging or several non-bridging ligands and (iii) hard ligands such as deprotonated amide groups are well known to stabilize metal ions in their high oxidation state such as
$\mathrm{Cu}(\mathrm{III}) .{ }^{[26]}$ Using the ligand $\mathrm{H}_{5} \mathrm{~L}$, a dinuclear alkoxo and acetatobridged complex, $\left[\left(\mathrm{H}_{2} \mathrm{~L}\right) \mathrm{Cu}_{2}(\mathrm{OAc})\right] \cdot\left(\mathrm{H}_{2} \mathrm{O}\right)_{2}(1)$ was prepared and characterized. Starting from complex 1 , we have focused on the generation and characterization of a new mixed-valent $\mathrm{Cu}(\mathrm{II}, \mathrm{III})$ dinuclear species by chemical and electrochemical oxidation.

\section{RESULTS AND DISCUSSION}

\section{Synthesis and X-ray crystallography}

The ligand $\mathrm{H}_{5} \mathrm{~L}$ was obtained in high yield $(87 \%)$, in one step by reaction of the commercially available 2-chloro-Nphenylacetamide with 1,3-diamino-2-propanal. The metallation of $\mathrm{H}_{5} \mathrm{~L}$ was performed in methanol by using two equivalents of copper(II) acetate salt in the presence of $\mathrm{Et}_{3} \mathrm{~N}$ as a base yielding complex 1. Two different $X$-ray crystal structures (1a and $1 \mathbf{b}$ ) were obtained from crystallization of complex 1 by slow evaporation of a solution either in ethanol/dichloromethane/dimethylformamide at room temperature (1a) or in dichloromethane/dimethylformamide at $4{ }^{\circ} \mathrm{C}(\mathbf{1 b})$. Crystals of $1 \mathrm{a}$ were of good quality and allowed complete structure refinement and determination. On the contrary the data collected for $\mathbf{1 b}$ provided a structure that is not refined according to standard crystallographic criteria and is therefore presented in SI (Figure S1). The ORTEP view of 1a is depicted in Figure 2.

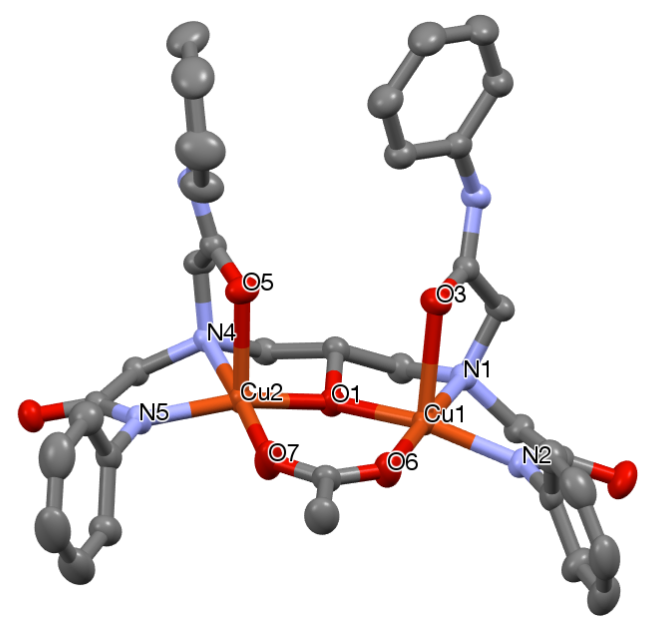

Figure 2. ORTEP representation (30\% ellipsoid probability) obtained from XRay crystal structures for $1 \mathrm{a}$. Solvent molecules and $\mathrm{H}$-atoms were omitted for clarity.

1a consists in a binuclear complex in which the copper ions are bridged by the alkoxide group of the ligand and an acetate moiety. In both cases, the ligand was tri-deprotonated and two amide functions remained protonated. The equatorial positions of each copper are occupied by the $\mathrm{N}$-atom from deprotonated amide groups, the $\mathrm{N}$ and the O-atoms of the ethanolamine moieties, as well as one O-atom from the bridging acetate ligand. The O-atoms from the pendant amide arms that remained 
protonated are found in the apical positions. Selected bond lengths and distances are listed in Table 1. The structural index calculated as defined by Addison et al. ${ }^{[27]}$ is $\tau=0.02$ for both Cu1 and $\mathrm{Cu} 2$ indicating that the copper ions are in square-pyramidal geometries. The structure $\mathbf{1 b}$ is very similar to $\mathbf{1 a}$. Although main geometric features are generally quite similar in both cases, one striking difference is observed in distances between the two apical arms (materialized by $\mathrm{O} 5-\mathrm{O} 3$ distance) and the two equatorial amide arms (materialized by N5-N2 distance). The O5-O3 distance is found elongated in $\mathbf{1 b}$ as compared to $\mathbf{1 a}$. Meanwhile the N5-N2 distance is shortened in 1b as compared to $1 \mathrm{a}$ while the $\mathrm{Cu}(1)-\mathrm{Cu}(2)$ distance remains very similar. These two structures possibly describe two limit conformations adopted by 1 - closed (1a) and open (1b) leading to the image of a butterfly-flapping complex.

Table 1. Selected bond lengths and angles for $\mathbf{1 a}$

\begin{tabular}{llll}
\hline \multicolumn{2}{c}{ Bond lengths in $\AA$} & \multicolumn{2}{c}{ Bond angle in deg. } \\
\hline Cu1-O1 & $1.9225(17)$ & O1-Cu1-O6 & $96.12(8)$ \\
Cu1-O6 & $1.937(2)$ & O1-Cu1-N1 & $83.89(8)$ \\
Cu1-N1 & $2.064(2)$ & N1-Cu1-N2, & $82.78(9)$ \\
Cu1-N2 & $1.963(2)$, & N2-Cu1-O6 & $96.12(9)$ \\
Cu1-O3 & $2.3359(18)$ & O3-Cu1-O1 & $90.78(7)$ \\
Cu2-O1 & $1.9022(18)$ & O3-Cu1-N1 & $79.18(7)$ \\
Cu2-O7 & $1.931(3)$ & O1-Cu2-O7 & $95.92(9)$ \\
Cu2-N4 & $2.095(2)$ & O1-Cu2-N4 & $85.31(8)$ \\
Cu2-N5 & $1.935(2)$ & N4-Cu2-N5 & $83.59(8)$ \\
Cu2-O5 & $2.2257(18)$ & N5-Cu2-O7 & $94.09(9)$ \\
& & O5-Cu2-N4 & $80.44(7)$ \\
& & O5-Cu2-N5 & $98.23(8)$ \\
\hline
\end{tabular}

\section{Magnetic properties.}

Magnetic susceptibility measurements were performed for 1 both in the solid state (crystals of 1a) and in DMF solution. In the solid state, the temperature dependence of the product of the molar susceptibility and the temperature $\chi$ shows a typical profile of ferromagnetic coupling interactions (Figure 3 ). The rapid decrease of $\chi$ below $20 \mathrm{~K}$ may be due to intermolecular antiferromagnetic interaction. ${ }^{[28]}$ The data could be fitted by using a model for two coupled spins $(S=1 / 2)$ described by the spin Hamiltonian $\mathbf{H}=-J \mathbf{S}_{1} . \mathbf{S}_{2}$ and using an additional mean field approximation to reproduce intermolecular interactions. Parameter optimization yielded a coupling constant $J=53.8 \mathrm{~cm}^{-1}$ with $\mathrm{g}=2.20$. Others $\mu$-alkoxo- $\mu$-monocarboxylato dinuclear $\mathrm{Cu}$ (II) complexes have been structurally and magnetically studied in the literature allowing the establishment of magnetostructural correlations. ${ }^{[29,30]}$ From these studies, a Cu1-O1-Cu2 angle $(\theta)$ greater than $116.5^{\circ}$, as it is the case in $1\left(127.54^{\circ}\right)$, should lead to an antiferromagnetic coupling while ferromagnetism appears for smaller values of $\theta \cdot{ }^{[28]}$ However, 1 exhibits a significant roof-shaped distortion ${ }^{[31]}$ which is measured by the dihedral $(\delta)$ angle between two copper coordination planes $\left(4.64^{\circ}\right.$ in $\left.1 \mathrm{a}\right)$ as well as a significant out-of-plane displacement of the carbon atom of the alkoxo group with respect to the Cu1-O1-Cu2 plane $(0.76 \AA$ in 1a). These factors have been shown to depress the antiferromagnetic interaction leading to a ferromagnetic coupling ${ }^{[31,32]}$ and may explain that ferromagnetic coupling prevails in 1 . Surprisingly, magnetic susceptibility measurements performed for $\mathbf{1}$ in DMF solution (Figure S3) lead to different results, i.e. small antiferromagnetic coupling $\left(\mathrm{J}=-3.1 \mathrm{~cm}^{-1}\right)$. The switch from ferro- to antiferromagnetic coupling in solution might however be the result of small geometric rearrangement and in particular around the alkoxo-bridging motif modifying essential parameters for exchange interactions.

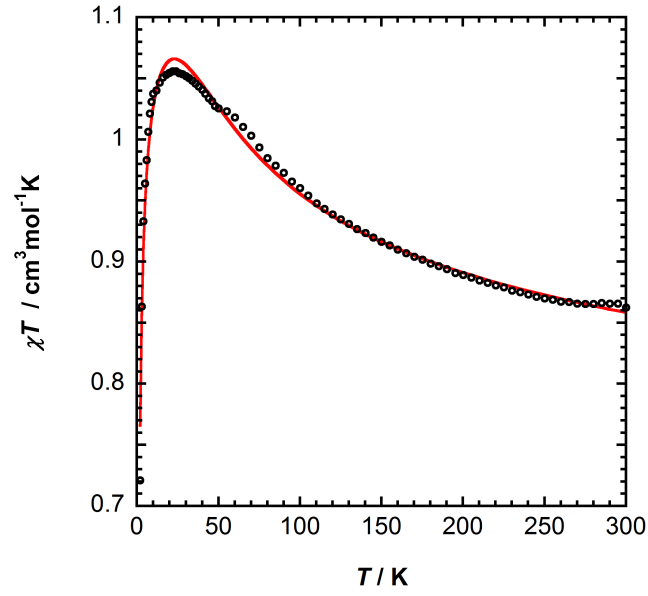

Figure 3. Temperature dependence of 1 in the solid state. Parameters from the fit: $J=53.8 \mathrm{~cm}^{-1}, \mathrm{~g}=2.20, \mathrm{zJ}=-0.97 \mathrm{~cm}^{-1}, C_{/ C u}=-60.6 .10^{-6} \mathrm{~cm}^{3} \mathrm{~mol}^{-1}$ goodness of fit $R=7 \cdot 6 \cdot 10^{-5}$.

\section{Studies of 1 in DMF solution.}

In order to get a better picture of the structure of 1 in DMF solution, we first performed mass spectrometry analysis. The ESI-MS spectrum of 1 in DMF/MeOH (Figure S2) exhibits two fragments centered at $\mathrm{m} / \mathrm{z}=805.1466$ and 827.1285 assigned to $[\mathrm{M}+\mathrm{H}]^{+}$and $[\mathrm{M}+\mathrm{Na}]^{+}$respectively, suggesting that 1 retains its coordination sphere in DMF solution, including the bridging acetate moiety.

NMR studies of 1 in deuterated DMF were also performed. ${ }^{1} \mathrm{H}$ NMR spectra of 1 and of sodium acetate salt were recorded in deuterated DMF. Comparison of the two spectra allows to conclude that no resonance attributed to free acetate that could have been released in solution are detected (Figure S4 and Figure S5), confirming that acetate is maintained in the coordination sphere of the copper ions, as already suggested by ESI-MS experiments. The ${ }^{1} \mathrm{H}$ NMR spectrum of $\mathbf{1}$ is rather complicated with numerous resonances (33 resonances detected) in a large range of chemical shift from +25 to $-10 \mathrm{ppm}$ as expected for a paramagnetic compound (Figure S4). ${ }^{[33,34]}$ The numerous resonances detected are consistent with the presence of several conformers in solution. To further investigate the behavior of the complex in DMF solution, 2D ${ }^{1} \mathrm{H}$ NMR experiments were performed. The NOESY spectrum of 1 at 343 $\mathrm{K}$ (Figure 4 ) exhibits four cross peaks $(11.33,10.48,10.27$ and 
$9.60 \mathrm{ppm}$ ) attributed to the correlation between the labile protons from the protonated amide arms of 1 and residual water molecules (black surrounded cross peaks). These results suggest that two to four different conformations for complex 1 coexist in solution, possibly a mixture between asymmetric conformations displaying two non-equivalent protonated amide arms for each conformation and/or different symmetric conformations. Integration of the resonances attributed to the $\mathrm{NH}$ amide groups of the different conformers based on NOESY experiments gives a ratio of 1:1:1:2 at $343 \mathrm{~K}$. Similar ratios for the different conformers were determined in the temperature range of 273 to $343 \mathrm{~K}$ and no equilibrium between the different conformers can be detected in this temperature range (Figure S6, Table S1). These results suggest that at least 3 different conformers coexist in solution at room temperature as well as at higher temperatures. As already observed in the solid state, the ligand provides a great flexibility around the dicopper center. The two limit conformations that were characterized in the solidstate display different conformations of the protonated amide arms. It is therefore not surprising that different conformations of these pendant amide arms can be found in solution as well, without significantly altering the dicopper core. Finally, DOSY ${ }^{1} \mathrm{H}$ NMR experiments were performed to evaluate the diffusion coefficient of 1 , which was calculated as the average of the $D$ values determined for each peak attributed to the different conformers (Figure S7). The mean $D$ value for 1 is $5.410^{-10}$ $\mathrm{m}^{2} . \mathrm{s}^{-1}$ at $293 \mathrm{~K}$.

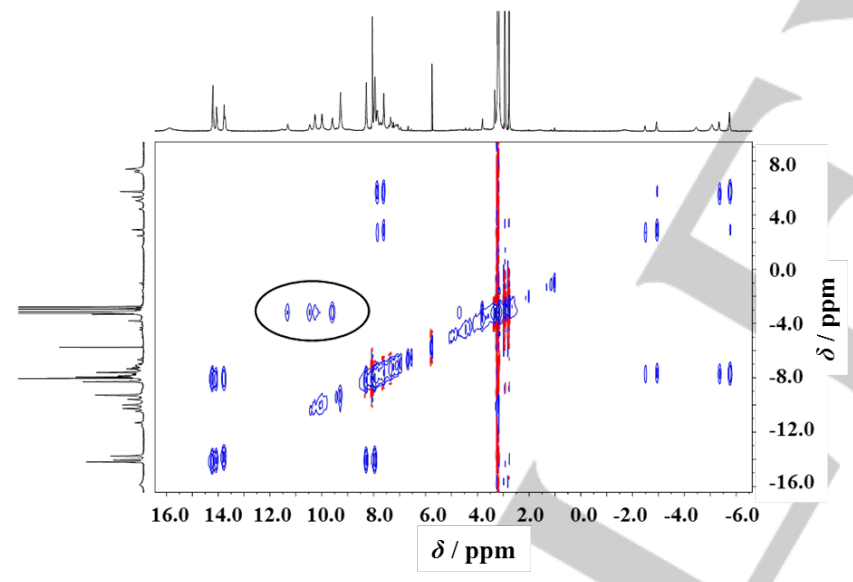

Figure 4. NOESY spectrum of 1 in N,N-Dimethylformamide-d7 at $343 \mathrm{~K}$. Cross peaks surrounded in black correspond to the correlation between protons from protonated amide arms and residual water molecules.

\section{Electrochemical studies.}

Cyclic voltammetry (CV) of $\mathbf{1}$ was performed in DMF in the presence of $0.1 \mathrm{M} \mathrm{NBu}_{4} \mathrm{PF}_{6}$ under argon and at room temperature. All potentials are referenced versus the $\mathrm{Fc}^{+} / \mathrm{Fc}$ redox couple. As shown in Figure 5 , an oxidation peak is detected at $E_{\mathrm{pa}}(1)=0.63 \mathrm{~V}$ at a scan rate $v=0.1 \mathrm{~V} \mathrm{~s}^{-1}$. It is fully irreversible in the investigated scan-rate range $\left(0.005 \mathrm{~V} \mathrm{~s}^{-1}<v<\right.$ $\left.30 \mathrm{~V} \mathrm{~s}^{-1}\right)$ and even at low temperature $\left(-40^{\circ} \mathrm{C}\right)$. This oxidation peak is associated to several reduction peaks on the back scan
(Figure 5 and Figure S8). The sharp oxidation peak at $-0.25 \mathrm{~V}$ on the return scan can be ascribed to the dissolution of an eletrogenerated $\mathrm{Cu}(0)$ complex. When scanning towards negative potentials, a single reduction peak is detected at $E_{\mathrm{pc}}(2)$ $=-1.34 \mathrm{~V}$ vs $\mathrm{Fc}^{+} / \mathrm{Fc}$ while several oxidation peaks associated to the reduction process are observed on the reverse scan between $-0.6 \mathrm{~V}$ and $0.2 \mathrm{~V}$ (Figure 5 and Figure S9). Roomtemperature exhaustive electrolysis either in oxidation or reduction leads to degradation of the electrochemically oxidized or reduced complexes. The bulk electrolysis time-scale being about an hour, the observed degradation is not surprising.

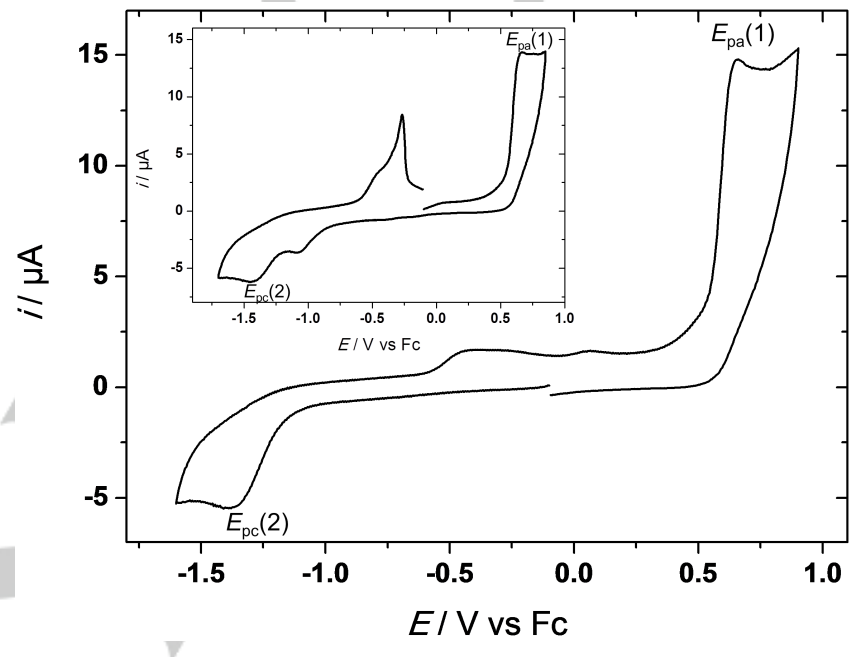

Figure 5. CV at a glassy carbon electrode of complex $1(0.50 \mathrm{mM})$ in DMF / $\mathrm{NBu}_{4} \mathrm{PF}_{6} 0.1 \mathrm{M}$ under Argon at $v=0.1 \mathrm{~V} \mathrm{~s}^{-1}$, negative scanning, inset: $v=0.1$ $\mathrm{V} \mathrm{s}^{-1}$, positive scanning.

Plots of anodic or cathodic peak currents $\left(i_{\mathrm{pa}}(1)\right.$ and $i_{\mathrm{pc}}(2)$ respectively) against $v^{1 / 2}$ follow linear variations, as expected for a diffusion-controlled electrochemical process (Figures S10). ${ }^{[35]}$ The dependence of the current intensity $i_{p} v s$. $v^{1 / 2}$ was used in order to determine the number of electrons exchanged in the redox processes $(n)$. This was performed by assuming a simple EC mechanism to account for irreversibility ( $E=$ Electrochemical, $\mathrm{C}=$ Chemical), knowing the value of the diffusion coefficient from DOSY experiments $\left(D=5.410^{-6} \mathrm{~cm}^{2} \mathrm{~s}^{-1}\right)$. Calculations give $n=$ 0.9 and 1.6 for the cathodic and anodic processes respectively. ${ }^{[36]}$ In agreement with $\mathrm{CV}$ studies that show that free acetate can be oxidized irreversibly at $E_{\mathrm{pa}}(3)=0.78 \mathrm{~V} v \mathrm{~s}$. $\mathrm{Fc}^{+} / \mathrm{Fc}$ in the same experimental conditions (Figure S11), it seems likely that oxidation of complex 1 at $E_{\mathrm{pa}}(1)$ leads to fast release of acetate and possible binding of DMF solvent (Scheme 3 ). In that case, acetate can itself be oxidized when scanning positively beyond $E_{\mathrm{pa}}(3)$. As a result, the number of electron involved in the oxidation process is greater than one. Hence, these voltammetric studies strongly suggest that complex 1 can be reduced or oxidized in a monoelectronic manner, and that the oxidation process induces a fast chemical unbinding of acetate. Note that unbinding of acetate before oxidation of 1 can be excluded on the basis of previously mentioned ESI-MS and 
NMR experiments. Thus, the redox behavior of 1 is somewhat similar to those obtained with analogous dinuclear hydroxobridged $\mathrm{Cu}(\mathrm{II})$ complexes which can also be oxidized in a monoelectronic manner. ${ }^{[23,24]}$ The potential required for the oxidation of $1\left(E_{\mathrm{pa}}=0.63 \mathrm{~V}\right)$ lies between those found for naphthyridine-based $\left(E^{0}=1.26 \mathrm{~V}\right)$ and pyridine(dicarboxamide)based $\left(E^{0}=0.18 \mathrm{~V}\right)$ dinuclear complexes. Assuming similar donor properties for acetate and hydroxo bridging groups, such difference can be correlated to the charge of the resulting complexes (neutral for $\mathbf{1}$, dicationic for the naphtyridine-based complex, and monoanionic for the macrocycle-based species).
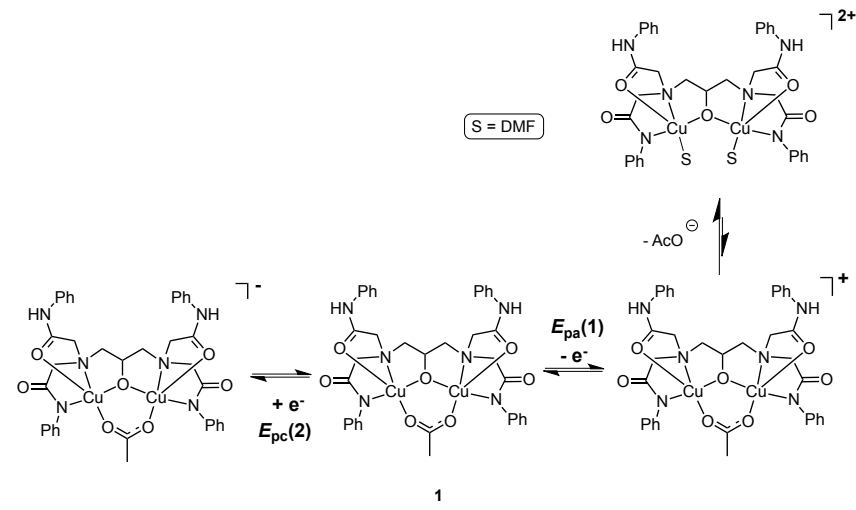

Scheme 3. Proposed redox pathways for complex 1 from voltammetric data.

\section{Characterization of the one-electron oxidized species $1^{+}$.}

Spectroelectrochemical experiments were carried out at room temperature for the UV-Vis spectroscopic characterization of the transient oxidized species $1^{+}$generated by electrochemistry. The 3D spectroscopic response of the complex obtained by thinlayer cyclic voltammetry (TLCV) upon oxidation is displayed in Figure 6.

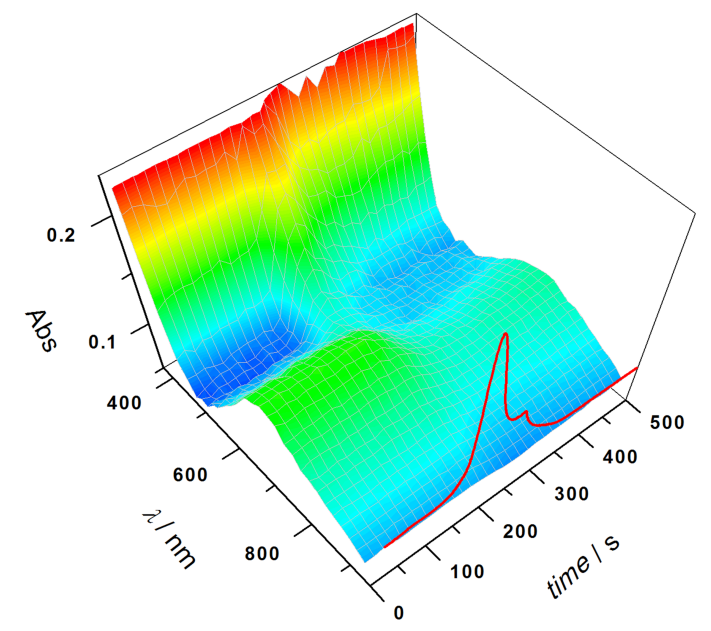

Figure 6. Room-temperature $3 D$ UV-Visible spectroscopic monitoring of electrochemical oxidation of complex $1(0.50 \mathrm{mM})$ in $\mathrm{DMF} / \mathrm{NBu}_{4} \mathrm{PF}_{6} 0.1 \mathrm{M}$ under $\mathrm{Ar}$ and at a glassy carbon electrode (optical path $0.2 \mathrm{~mm}$ ); red curve: corresponding TLCV $(v=5 \mathrm{mV} / \mathrm{s})$.
Three zones can be drawn from the experimental data. Before oxidation, 1 displays two absorption bands at $\lambda_{\max }=711 \mathrm{~nm}(\mathrm{~d}-\mathrm{d}$ transition) and $380 \mathrm{~nm}(\mathrm{CT})$. When oxidation starts $(t>150 \mathrm{~s})$, both bands decrease in intensity and a new transition appears in the $400-500 \mathrm{~nm}$ wavelength range (Figure 7B). A maximum absorption is reached for this newly formed band at $t=220$ seconds. Differential superposition of the spectra indicates that a maximal absorption is obtained at $\lambda_{\max }=463 \mathrm{~nm}$ (Figure 7C). Beyond 220 seconds, this band decreases, showing the transient character of the generated oxidized species (Figure 6 and Figure 7D). Back cycling toward negative potential ( $t>260$ seconds) shows a slight increase of the $d-d$ band at $711 \mathrm{~nm}$, but without reaching the initial absorbance level (Figure 6), as expected from the irreversible character of the TLCV. These results indicate that oxidation occurs likely on one copper center since the $d$-d transition is affected by the electron transfer reaction. The generated species, which displays an absorption band at $463 \mathrm{~nm}$, is transiently stable for several seconds at room temperature before decaying into a new species.
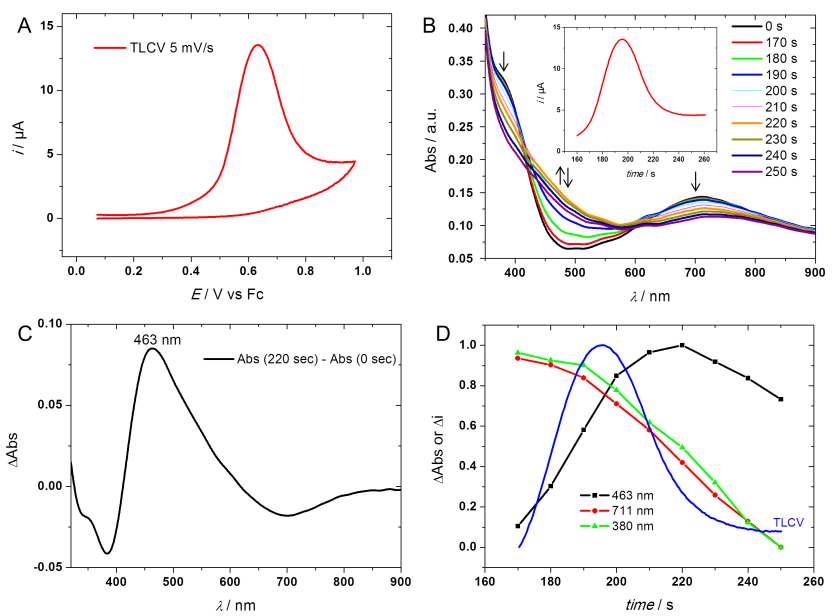

Figure 7. A) Room-temperature TLCV $(v=5 \mathrm{mV} / \mathrm{s})$ at a glassy carbon electrode of $1(0.50 \mathrm{mM})$ in DMF / NBu $4 \mathrm{PF}_{6} 0.1 \mathrm{M}$ under $\mathrm{Ar}$; $\left.\mathrm{B}\right) 2 \mathrm{D}$ UV-Vis spectra of complex 1 upon TLCV experiment $(5 \mathrm{mV} / \mathrm{s})$; Inset: Variation of current with time during the CV; C) UV-Vis differential spectrum at $\lambda=463 \mathrm{~nm}$ between $t=220$ seconds $t=0$ seconds; D) Plots of relative absorbance $v s$. time during the spectroelectrochemical measurements at different wavelengths: $\lambda=$ $463 \mathrm{~nm}$ (black), $\lambda=711 \mathrm{~nm}$ (red), $\lambda=380 \mathrm{~nm}$ (green). Blue curve: corresponding TLCV $(5 \mathrm{mV} / \mathrm{s})$.

In order to further investigate $\mathbf{1}^{+}$, Electron Paramagnetic Resonance (EPR) experiments were carried out. Complex 1 is EPR silent (X-band, $120 \mathrm{~K}$ ). Oxidation of the neutral complex 1 was performed in $\mathrm{CH}_{2} \mathrm{Cl}_{2} / \mathrm{DMF} 9 / 1$ at $-60^{\circ} \mathrm{C}$ by adding 1 equiv. of $\mathrm{NOSbF}_{6}$ as one-electron oxidant. The chemical generation of $1^{+}$causes the appearance of a transient EPR signal. The $120 \mathrm{~K}$ continuous-wave (cw) X-Band EPR spectrum of the unstable species $1^{+}$is depicted in Figure 8 . The EPR signal of $1^{+}$quickly decreases after a few minutes at $-60^{\circ} \mathrm{C}$ to completely disappear, consistent with the unstable character of the oxidized species in agreement with the electrochemical studies. The maximum intensity of the signal accounts for ca. $20 \%$ of intensity as 
referred to the initial concentration of 1 . The spectrum of $1^{+}$ displays typical $S=1 / 2$ axial signal with a four-line pattern in $g_{\|}$ region consistent with hyperfine interaction with only one $\mathrm{Cu}(\mathrm{II})$ ion, and therefore with a valence-localized $\mathrm{Cu}(\mathrm{II}) \mathrm{Cu}(\mathrm{III})$ species as observed for the two already reported ones. ${ }^{[23,24]}$ The simulation parameters point to a dominant $d_{x 2-y 2}$ electronic ground-state and are consistent with a $\mathrm{Cu}(\mathrm{II})$ ion bound axially to 2 nitrogens and one or two oxygen-containing ligands ( $g_{/ /}=$ 2.356 and $\left.A_{\|}(\mathrm{Cu})=126 \mathrm{G}\right) \cdot{ }^{[37,38]}$ The expanded second derivative of the perpendicular region of the EPR spectrum of $1^{+}$ is shown in Figure 8 (inset). It reveals the presence of superhyperfine lines resulting from the interaction between one nitrogen nucleus $(I=1)$ from the first coordination sphere and the single unpaired electron $(S=1 / 2$ ) of the copper(II) ion providing a coupling constant of $A_{N}=16.8 \mathrm{G}$. This relatively strong superhyperfine interaction indicates that the $\mathrm{Cu}(\mathrm{II})$ ion interacts with an axially bound nitrogen (most likely the deprotonated amide ligand) $)^{[39]}$ and that only small deviation from planarity is expected. This strongly supports the fact that the overall structure of the complex is maintained in solution. Altogether, the EPR data point to a localized mixed-valent $\mathrm{Cu}(\mathrm{II}) \mathrm{Cu}(\mathrm{III})$ formulation for $\mathbf{1}^{+}$.

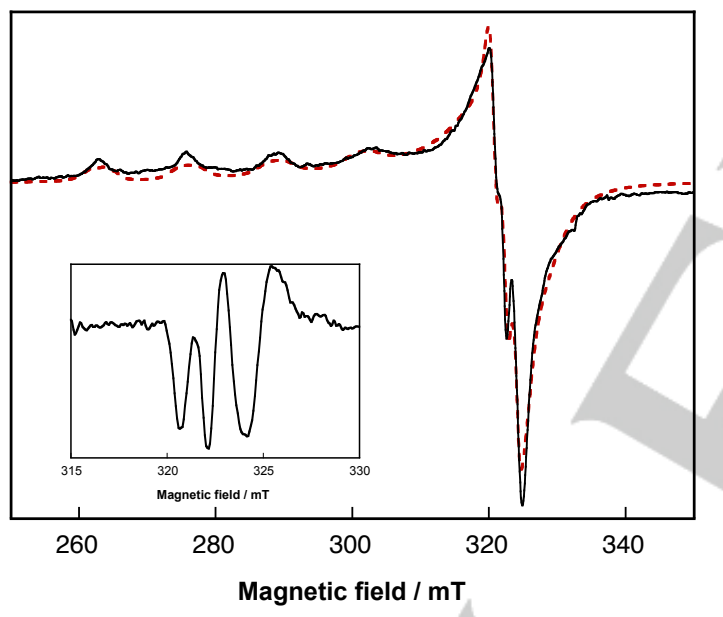

Figure 8. X-band EPR spectrum of $0.5 \mathrm{mM}$ solution of chemically generated $1^{+}$at $-60^{\circ} \mathrm{C}$ in $\mathrm{CH}_{2} \mathrm{Cl}_{2}+10 \%$ DMF. Solid line: experimental spectrum, dotted red line: simulation. Parameters $g_{z}=2.356 g_{y}=2.058, g_{x}=2.058, A_{\|}(C u)=126$ $\mathrm{G}, \mathrm{A}_{\perp}\left({ }^{14} \mathrm{~N}\right)=16.8 \mathrm{G}$. Inset: Derivative spectrum. Experimental conditions: microwaves frequency $9.31 \mathrm{GHz}$, microwave power $=20 \mathrm{~mW}$, modulation amplitude $0.3 \mathrm{mT}, T=120 \mathrm{~K}$.

\section{DFT-calculations}

DFT calculations were performed in order to propose a structure for the oxidized form of 1 . Different structures, including or not the acetate moiety, were computed: a structure similar to the starting complex with the bridging acetate ligand $(a)$ a structure with the acetate bound in a monodentate fashion on one copper (b) a structure with one DMF on one $\mathrm{Cu}$ and one monodentate acetate ligand on the other $\mathrm{Cu}(c)$ and a structure with one monodentate DMF bound on one copper (d) (Figure 9 and
Figure 9. DFT-optimized structure and selected metrical parameters for the relevant oxidized form of 1 (form $b$ )

The oxidized form of $\mathbf{1}$ including one monodendate acetate ligand (form $b$ ) is the only structure that provided a localized mixed-valent Cull Culll species (Figure 9). This structure could be formed upon oxidation of 1 before complete acetate release and DMF binding. This assignment is supported by the spin density plot and the Singly Occupied Molecular Orbital (SOMO) that are found mainly developed on one copper center (Figure 10). The SOMO, located on the $\mathrm{Cu}(\mathrm{II})$ center, displays a dominant $\mathrm{Cu}$ $3 d x^{2}-y^{2}$ character, in agreement with the experimental EPR spectrum. In addition, time-dependent (TD) DFT calculations were performed to predict the UV-Vis spectrum (Figure S14). A ligand-to- $\mathrm{Cu}(\mathrm{III})$ transition is predicted at ca. $457 \mathrm{~nm}$ (Figure S15), which is in fair agreement with the observed $463 \mathrm{~nm}$ transition during spectroelectrochemistry experiments.

Figure S12). Singly Occupied Molecular Orbitals (SOMOs) were calculated for the different optimized forms of $1^{+}$. The SOMOs of both copper centers and on one phenyl moiety of the ligand (Figure S13). These data are not in agreement with the experimental description of $\mathbf{1}^{+}$as a localized mixed-valent intermediate.

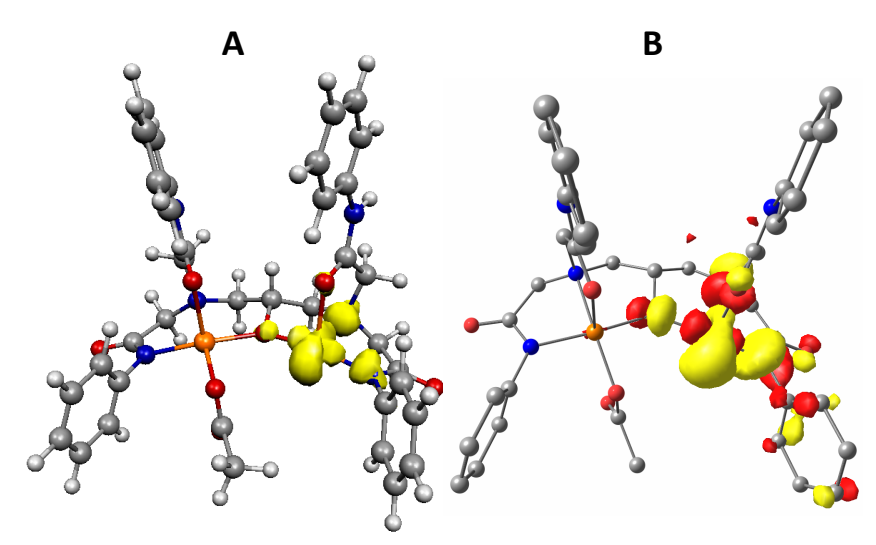

Figure 10. A) Spin density plot and B) localized SOMO for the relevant oxidized form of 1 
Altogether our data indicate that the computed form $b$ of $1^{+}$can account for the experimentally observed properties of the intermediate and therefore represents a possible structure for the mixed-valent $\mathrm{Cu}(\mathrm{II}) \mathrm{Cu}(\mathrm{III})$ species.

\section{Conclusions}

In the present work, we have shown that the use of polydentate amide-containing ligand such as $\mathrm{H}_{5} \mathrm{~L}$ provides a high flexibility of the corresponding dicopper complex, which can adopt several conformations both in solid-state and in solution. The presence of amide ligands favors the formation of $\mathrm{Cu}(\mathrm{III})$ redox state and spectroscopic characterizations of the monooxidized complex indicate the formation of a mixed-valent $\mathrm{Cu}^{\prime \prime} \mathrm{Cu}^{\text {III }}$ species. DFTcalculations were performed to propose a possible structure for this intermediate. So far, this study represents the third example of characterization of such mixed-valent species generated from bridged dicopper complexes. Interestingly, since the acetate bridge replacement is possible and since acetate seems to unbind from copper upon oxidation, further studies will aim at stabilizing the mono-oxidized species by suitable ligand design. The development of new $\mathrm{Cu}(\mathrm{II}) \mathrm{Cu}(\mathrm{III})$ complexes with different bridges/cores will be coupled to catalytic studies for the activation of $\mathrm{C}-\mathrm{H}$ bonds, as mimics of $\mathrm{pMMO}$ metalloenzyme active site.

\section{Experimental Section}

General. The solvents used for chemical reactions, electrochemistry and spectroscopic characterization were purified using the solvent purification system Innovative Technology PS-MD-5. The supporting electrolyte $\mathrm{NBu}_{4} \mathrm{BF}_{4}$ was synthesized from $\mathrm{NBu}_{4} \mathrm{OH}$ (Acros) and $\mathrm{HPF}_{6}$ (Aldrich). It was dried under vacuum for 48 hours at $100^{\circ} \mathrm{C}$ then kept under argon in the glovebox. Microanalysis was performed on an Elementar Thermo Finnigan EA 1112. ${ }^{1} \mathrm{H}-\mathrm{NMR}$ spectra were recorded at room temperature using a Brucker-Avance III Nanobay spectrometer operating at $300 \mathrm{MHz}$. A Bruker Avance III spectrometer operating at $600 \mathrm{MHz}$, equipped with a Variable Temperature Control unit and a triple resonance high-resolution probe producing gradients with a maximum strength of $60 \mathrm{G.cm}$ ${ }^{1}$ was used for collection of 1D, 2D and DOSY NMR spectra of complex 1 at the required temperature. All Chemical shifts are given relative to residual peak of solvent $\left(\delta_{\mathrm{CHCl}}=7.26 \mathrm{ppm}\right)$. Standard DOSY spectra were recorded by a conventional pulse sequence, based on the stimulated echo and incorporated bipolar gradient pulses and an eddy-current delay (BPPLED), ${ }^{[40,41]}$ the diffusion delay $\Delta$ was set at $25 \mathrm{~ms}$, the gradient strength, $\mathrm{g}$, was linearly incremented in 32 steps from $2 \%$ to $9 \%$ of its maximum value, and 8 scans were recorded for each experiment.

ESI-MS analyses were performed using a SYNAPT G2 HDMS (Waters) spectrometer equipped with a pneumatically assisted Atmospheric Pressure Ionization (API) source. Samples were ionized by positive electrospray mode as follows: ion-spray voltage: $2.8 \mathrm{kV}$; orifice lens: $60 \mathrm{~V}$ and $80 \mathrm{~V}$ for $\mathrm{H}_{5} \mathrm{~L}$ and 1 respectively; nitrogen flux (nebulization): 100 L. $\mathrm{h}^{-1}$. High resolution mass spectra (HRMS) were performed on a QStar Elite (Applied Biosystems SCIEX) spectrometer equipped with atmospheric pressure ionization source (API) pneumatically assisted. 1 was placed in a methanol/DMF/0.1 mM sodium chloride solution and $\mathrm{H}_{5} \mathrm{~L}$ was placed in a methanol/3 mM sodium acetate solution. All the measurements were done in triplicate. UV-visible spectra were recorded on a Varian Cary 50 spectrophotometer. Continuous wave (CW) X-band EPR measurements have been conducted at $120 \mathrm{~K}$ in frozen solution using a BRUKER ELEXSYS E500 equipped with a digital temperature controller $(80-300 \mathrm{~K})$. The simulations with automatic parameter fitting were performed for axial symmetry. ${ }^{[42]}$

Synthesis of $\mathrm{H}_{5} \mathrm{~L}$ : 1,3-diamino-2-propanol $(0.34 \mathrm{~g}, 3.8 \mathrm{mmol})$ was dissolved in DMF $(60 \mathrm{~mL})$ and 2-chloro-N-phenylacetamide (2.58 g, $15.2 \mathrm{mmol}), \mathrm{Nal}(1.14 \mathrm{~g}, 7.6 \mathrm{mmol})$ and $\mathrm{NaHCO}_{3}(1.28 \mathrm{~g}$, $15.2 \mathrm{mmol}$ ) were added. The resulting suspension was stirred at room temperature overnight. The solvent was removed until dryness. The product was then extracted with chloroform and washed three times with water $(40 \mathrm{~mL})$. The organic phase was dried over $\mathrm{Na}_{2} \mathrm{CO}_{3}$. The product was washed with diethyl ether $(3 \times 30 \mathrm{~mL})$ and dried under vacuum to give a white powder (2.05 g, 87\% yield). ${ }^{1} \mathrm{H} \mathrm{NMR}\left(300 \mathrm{MHz} ; \mathrm{CDCl}_{3}\right): \delta=9.54(\mathrm{~s}, 4 \mathrm{H})$, $7.55(\mathrm{~d}, \mathrm{~J}=7.8 \mathrm{~Hz}, 8 \mathrm{H}), 7.19(\mathrm{t}, J=7.8 \mathrm{~Hz}, 8 \mathrm{H}), 7.05(\mathrm{t}, J=7.4$ $\mathrm{Hz}, 4 \mathrm{H}), 3.87(\mathrm{~m}, 1 \mathrm{H}), 3.60-3.30(\mathrm{~m}, 8 \mathrm{H}), 2.71(\mathrm{~d}, J=13.0 \mathrm{~Hz}$, $2 \mathrm{H}), 2.46(\mathrm{~m}, 2 \mathrm{H})$. HRMS (ESI): $\mathrm{m} / \mathrm{z}$ calcd for $\mathrm{C}_{35} \mathrm{H}_{39} \mathrm{~N}_{6} \mathrm{O}_{5}{ }^{+}$ $[\mathrm{M}+\mathrm{H}]^{+}$623.2976, found: 623.2979.

Synthesis of $\left[\mathrm{H}_{2} \mathrm{LCu}_{2}(\mathrm{OAc})\right] \cdot\left(\mathrm{H}_{2} \mathrm{O}\right)_{2}$ (1): $\mathrm{Cu}(\mathrm{OAc})_{2}(0.17 \mathrm{~g}, 0.87$ $\mathrm{mmol})$ in $\mathrm{EtOH}(10 \mathrm{~mL})$ and $\mathrm{Et}_{3} \mathrm{~N}(0.30 \mu \mathrm{L}, 2.16 \mathrm{mmol})$ were added sequentially to a solution of $\mathrm{H}_{5} \mathrm{~L}(0.27 \mathrm{~g}, 0.43 \mathrm{mmol})$ in EtOH $(4 \mathrm{~mL})$. The solution turned green and was stirred at r.t overnight. A blue precipitate was collected by filtration, washed with diethyl ether $(10 \mathrm{~mL})$ and dried under vacuum $(0.273 \mathrm{~g}$, $75 \%)$. HRMS (ESI): $\mathrm{m} / \mathrm{z}$ calcd for $\mathrm{C}_{37} \mathrm{H}_{39} \mathrm{~N}_{6} \mathrm{O}_{7} \mathrm{Cu}_{2}[\mathrm{M}+\mathrm{H}]^{+}$: 805.1467, found: 805.1466; calcd for $\mathrm{C}_{37} \mathrm{H}_{38} \mathrm{~N}_{6} \mathrm{O}_{7} \mathrm{Cu}_{2} \mathrm{Na}$ $[\mathrm{M}+\mathrm{Na}]^{+}:$827.1286, found: 827.1285. Elemental Analysis calc. for $\mathrm{C}_{37} \mathrm{H}_{42} \mathrm{Cu}_{2} \mathrm{~N}_{6} \mathrm{O}_{9}$ : C, 52.79; $\mathrm{H}, 5.03 ; \mathrm{N}, 9.98$. Found: C, 52.50; $\mathrm{H}, 4.76$; N, 9.97 .

Magnetic properties. Magnetic measurements were carried out with a Quantum Design SQUID Magnetometer with an applied field of $1000 \mathrm{G}$. The independence of the susceptibility value with regard to the applied field was checked at room temperature. Powder sample was measured in a gelatin capsule. For solution measurement, the frozen sample (molar concentration $4.510^{-2} \mathrm{~mol}^{-\mathrm{I}^{-1}}$ ) was sealed under vacuum in a quartz glass tube. To avoid artifacts, this sample holder was symmetrized with another quartz glass tube. ${ }^{[43]}$ The susceptibility data were corrected for the sample holder registered in the same conditions and the diamagnetic contributions as calculated from tables of Pascal's constants.

The data were fitted by using a model for two coupled spins ( $\mathrm{S}=$ $1 / 2$ ) described by the spin Hamiltonian $\mathbf{H}=-\boldsymbol{J} \mathbf{S}_{1} \cdot \mathbf{S}_{2}$. An additional 
mean field approximation was added to reproduce intermolecular interactions: $\chi^{T}=\left[\chi\right.$ dimer $\left./\left(1-\mathrm{ZJ} \mathrm{J}_{\text {dimer }} / \mathrm{Ng}^{2} \beta^{2}\right)+C\right] T$ where $C$ is a diamagnetic contribution. The error in the fit was calculated from the following expression where $\chi_{\exp }$ and $\chi_{\text {cal }}$ are the observed and calculated magnetic susceptibilities respectively: $\left.R=\Sigma\left(\begin{array}{lll}\chi & \text { cal }-\chi & \exp \end{array}\right)^{2} / \Sigma\left(\begin{array}{ll}\chi & \exp \end{array}\right)^{2}\right)$.

X-Ray Crystallographic Data Collection and Refinement of the Structures. Single crystals were grown by slow evaporation of a concentrated solution of compound $\mathbf{1}$ in either ethanol/dichloromethane/dimethylformamide (1/1/1) (conformer 1a) or dichloromethane/dimethylformamide (9/1) (conformer 1b), respectively. The intensity data for both compounds were collected at $293 \mathrm{~K}$ on a Rigaku Oxford Diffraction SuperNova diffractometer using CuKa radiation $(\lambda=1.54184 \AA \AA)$. Data collection, cell refinement and data reduction were performed with CrysAlisPro (Rigaku Oxford Diffraction). Using Olex2, ${ }^{[44]}$ the structure were solved with ShelXS ${ }^{[44]}$ using Direct Methods and refined with the ShelXL ${ }^{[45]}$ refinement package using Least Squares minimization. Unfortunately the crystals of $\mathbf{1 b}$ were not suitable enough to complete a good structure refinement despite the fact that the main features of the complex could be characterized without ambiguities. Both forms co-crystallize with solvent molecules, one ethanol and one water molecules for $\mathbf{1 a}$, two dichloromethane and several highly unidentified disordered solvent molecules for $\mathbf{1 b}$. The hydrogen atoms were found experimentally for $\mathbf{1 a}$ and were refined with riding coordinates to their parent atoms and with their Uiso parameters fixed to 1.2Ueq(parent atom) for the $\mathrm{C}(\mathrm{H})$ and $\mathrm{C}(\mathrm{H}, \mathrm{H})$ groups and to 1.5 Ueq(parent atom) for the $\mathrm{C}(\mathrm{H}, \mathrm{H}, \mathrm{H})$ groups. The crystallographic data for $1 \mathrm{a}$ are reported in Table 2.

Table 2. Crystallographic data for compound 1a

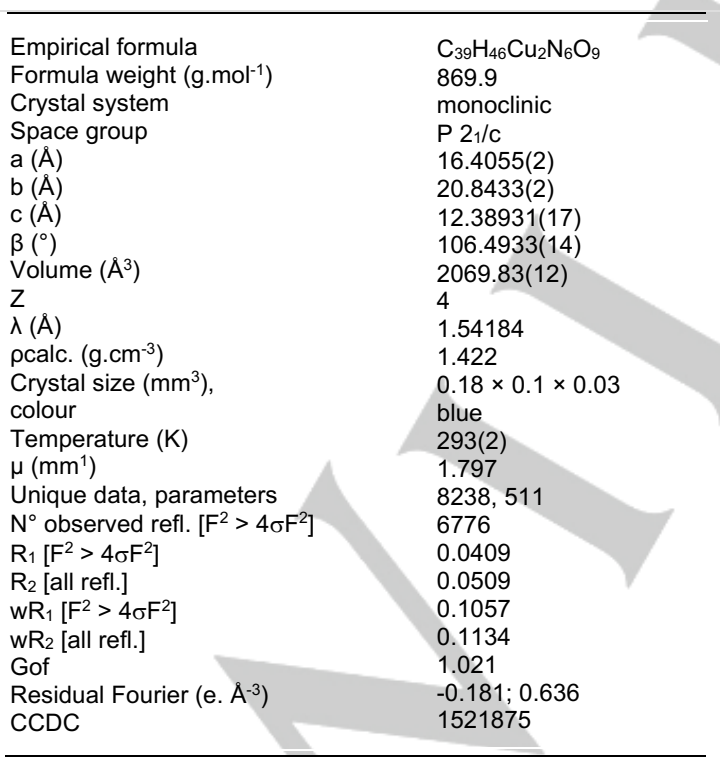

$w=1 /\left[\sigma^{2}\left(\mathrm{Fo}^{2}\right)+(0.0578 \mathrm{P})^{2}+1.2308 \mathrm{P}\right]$ where $\mathrm{P}=\left(\mathrm{Fo}^{2}+2 \mathrm{Fc}^{2}\right) / 3$
Electrochemical studies. Electrochemical studies of the copper complex were performed in a glovebox (Jacomex) $\left(\mathrm{O}_{2}<1 \mathrm{ppm}\right.$, $\mathrm{H}_{2} \mathrm{O}<1 \mathrm{ppm}$ ) with a home-designed 3-electrodes cell (WE: glassy carbon, $\mathrm{RE}$ : $\mathrm{Pt}$ wire in a $\mathrm{Fc}^{+} / \mathrm{Fc}$ solution, $\mathrm{CE}$ : $\mathrm{Pt}$ or graphite rod). The cell potential was controlled by an AUTOLAB PGSTAT 100 (Metrohm) potentiostat monitored by the NOVA software. Extra-dry DMF (Acros) was stored into the glovebox and used as received. Electrolyses were carried out with a home-designed 3-electrodes cell (WE: Graphite rod, RE: Pt wire in a $\mathrm{Fc}^{+} / \mathrm{Fc}$ solution, $\mathrm{CE}$ : graphite rod). Thin layer roomtemperature UV-Vis spectroelectrochemistry was performed with a specific home-designed cell in a reflectance mode (WE: glassy carbon, RE: Pt wire, CE: Pt wire). The UV-Vis optical fiber probe was purchased from Ocean Optics. Time-resolved UV-Vis-NIR detection was performed with a QEPro spectrometer (Ocean optics).

\section{DFT calculations}

All theoretical calculations were performed with the ORCA program package. ${ }^{[46]}$ Full geometry optimizations were undertaken for all complexes using the GGA functional BP86 ${ }^{[47]}$ and by taking advantage of the resolution of the identity (RI) approximation in the Split-RI-J variant ${ }^{[48]}$ with the appropriate Coulomb fitting sets ${ }^{[49]}$ Scalar relativistic effects were included with ZORA paired using the SARC def2-TZVP(-f) basis sets ${ }^{[50,51]}$ and the decontracted def2-TZVP/J Coulomb fitting basis sets for all atoms. Increased integration grids (Grid4 and GridX4 in ORCA convention) and tight SCF convergence criteria were used. Electronic structures and Molecular Orbital diagrams were obtained from single-point calculations using the hybrid functional B3LYP ${ }^{[52]}$. Increased integration grids (Grid4 and GridX4 in ORCA convention) and tight SCF convergence criteria were used in the calculations. For according to the experimental conditions solvent effects were accounted and we used the DMF solvent $(\varepsilon=37)$ within the framework of the conductor-like screening (COSMO) dielectric continuum approach. ${ }^{[53]}$ Optical properties were also predicted from additional single-point calculations using the hybrid functional B3LYP. Electronic transition energies and dipole moments for all models were calculated using time-dependent DFT (TDDFT) $)^{[54]}$ within the Tamm-Dancoff approximation. ${ }^{[55]}$ To increase computational efficiency, the RI approximation ${ }^{[56]}$ was used in calculating the Coulomb term, and at least 30 excited states were calculated in each case. For each transition, difference density plots were generated using the orca plot utility program and were visualized with the Chemcraft program. ${ }^{[57]}$

\section{Acknowledgements}

The authors acknowledge the French Research Agency (COMEBAC / ANR-13-BSO7-0018) for financial support.

Keywords: Bioinorganic chemistry $•$ Copper $•$ Electrochemistry • Mixed-valent species• Particulate methane monooxygenase 
[2] R. A. Periana, G. Bhalla, W. J. Tenn, K. J .H. Young, X. Y. Liu, O. Mironov, C. J. Jones, V. R. Ziatdinov, J. Mol Cat. A. 2004, 220, 7-25.

[3] a) S. Sirajuddin, A. C. Rosenzweig, Biochemistry 2015, 54, 2283-2294 b) M. O. Ross, A C. Rosenzweig J. Biol. Inorg. Chem., DOI 10.1007/s00775-016-1419-y

[4] R. Banerjee, Y. Proshlyakov, J. D. Lipscomb, D. A. Proshlyakov, Nature 2015, 518, 431-434.

[5] P. K. Grzyska, E. H. Appelman, R. P. Hausinger, D. A. Proshlyakov, Proc. Natl Acad. Sci. USA, 2010, 107, 3982-3987.

[6] E. I. Solomon, D. E. Heppner, E. M. Johnston, J. W. Ginsbach, J. Cirera, M. Qayyum, M. T. Kieber-Emmons, C. H. Kjaergaard, R. G. Hadt, L. Tian, Chem. Rev. 2014, 114, 3659-3853

[7] R. L. Lieberman, A. C. Rosenzweig, Nature 2005, 434, 177-182.

[8] A. S. Hakemian, K. C. Kondapalli, J. Telser, B. M. Hoffman, T. L. Stemmler, A. C. Rosenzweig, Biochemistry. 2008, 47, 6793-6801.

[9] S. M. Smith, S. Rawat, J. Telser, B. M. Hoffman, T. L. Stemmler, A. C. Rosenzweig, Biochemistry. 2011, 50, 10231-10240.

[10] S. I. Chan, S. S.-F. Yu, Acc. Chem. Res. 2008, 41, 969-979.

[11] R. A. Himes, K. Barnese, K. D. Karlin, Angew. Chem. Int. Ed. 2010, 49, 6714-6716

[12] R. Balasubramanian, S. M. Smith, S. Rawat, L. A. Yatsunyk, T. L. Stemmler, A. C. Rosenzweig, Nature. 2010, 465, 115-119.

[13] M. A. Culpepper, G. E. Cutsail III, W. A. Gunderson, B. M. Hoffman, A. C. Rosenzweig, J. Am. Chem. Soc. 2014, 136, 11767-11775.

[14] D. A. Quist, D. E. Diaz, J. J. Liu, K. D. Karlin, J. Biol. Inorg. Chem. DOI 10.1007/s00775-016-1415-2.

[15] J. S. Woertink, P. J. Smeetsa, M. H. Groothaert, M. A. Vance, B. F. Sels, R. A. Schoonheydt, E. I. Solomon, Proc. Natl. Acad. Sci. USA. 2009, 106, 18908-18913

[16] P. Haack, C. Limberg, Angew. Chem. Int. Ed. 2014, 53, 4282-4293.

[17] S. I. Kazuki, D. T. Kamachi, Y. Shiota, K. Yoshizawa, Inorg. Chem. 2016, 55, 2771-2775.

[18] a) W. Keown, J. B. Gary, T. D. P. Stack, J Biol Inorg Chem DOI 10.1007/s00775-016-1420-5 b) J. Serrano-Plana, I. Garcia-Bosch, A. Company, M. Costas, Acc. Chem. Res. 2015, 48, 2397-2406 d) J. Y. Lee, K. D Karlin, Curr. Op. Chem. Biol. 2015, 25, 184-193

[19] a) C. Citek, B. L. Lin, T. E. Phelps, E. C. Wasinger, T. D. P. Stack, J. Am. Chem. Soc. 2014, 136, 14405-14408 b) C. Citek, S. Herres-Pawlis T. D. P. Stack, Acc. Chem. Res. 2015, 48, 2424-2433

[20] K. Yoshizawa, Y. Shiota, Y, J. Am. Chem. Soc. 2006, 128, 9873-9881.

[21] Y. Shiota, K. Yoshizawa, Inorg. Chem. 2009, 48, 838-845.

[22] Y. Shiota, G. Juhaśz, K. Yoshizawa, Inorg. Chem. 2013, 52, 7907-7917.

[23] M. R. Halvagar, P. V. Solntsev, H. Lim, B. Hedman, K. O. Hodgson, E. I. Solomon, C. J. Cramer, W. B. Tolman, J. Am. Chem. Soc. 2014, 136, 7269-7272.

[24] J. A. Isaac, F. Gennarini, I. López, A. Thibon-Pourret, R. David, G. Gellon, B. Gennaro, C. Philouze, F. Meyer, S Demeshko, Y. Le Mest, M. Réglier, H. Jamet, N. Le Poul, C. Belle Inorg Chem. 2016, 55, 82638266.

[25] K. Selmeczi, M. Giorgi, G. Speier, E. Farkas, M. Réglier, Eur. J. Inorg Chem. 2006, 1022-1031.

[26] (a) A. Casitas, X. Ribas, Chem. Sci. 2013, 4, 2301-2318. (b) P. J. Donoghue, J. Tehranchi, C. J. Cramer, R. Sarangi, E. I. Solomon, W. B. Tolman, J. Am. Chem. Soc. 2011, 133, 17602-17605. (c) J. Tehranchi, P. J. Donoghue, C. J. Cramer, W. B. Tolman, Eur. J. Inorg. Chem. 2013 2013, 4077-4084.

[27] A. W. Addison, T. N. Rao, J. Reedijk, J. van Rijn, G. C. Verschoor, J. Chem. Soc, Dalton Trans. 1984, 1349-1348.
[28] C. H. Weng, S. C. Cheng, H. M. Wei, H. H. Wei, C. J. Lee, Inorg. Chim. Acta 2006. 359, 2029-2040.

[29] E. Ruiz, P. Alemany, S. Alvarez, J. Cano, J. Am. Chem. Soc. 1997, 119, 1297-1303.

[30] Magnetic Molecular Materials, NATO ASI Series C, vol. 140, (Eds.: D. Gatteschi, O. Khan, J. S. Miller, F. Palacio). Kluwer: Dordrecht, The Netherlands, 1985.

[31] (a) M. F. Charlot, O. Kahn, S. Jeannin, Y. Jeannin, Inorg. Chem. 1980, 19, 1410-1411. (b) I. Negodaev, C. de Graaf, R. Cabalool, V. V. Lukov, Inorg. Chim. Acta. 2011, 375, 166-172.

[32] E. Ruiz, P. Alemany, S. Alvarez, J. Cano, Inorg. Chem. 1997, 36, 36833688.

[33] NMR of Paramagnetic Molecules. G. N. La Mar, W. D. W. Horrocks, R. H. Holm, Academic Press, New York. 1973.

[34] Solution NMR of Paramagnetic Molecules. I. Bertini, C. Luchinat, G. Parigi, Elsevier: Amsterdam. 2001.

[35] Electrochemical Methods: Fundamentals and Applications. A. J. Bard, L. R. Faulkner, John Wiley \& Sons: New-York. 2000.

[36] Elements of Molecular and Biomolecular Electrochemistry. J.-M Savéant, John Wiley \& Sons: New-York: 2006. p 83

[37] J. Peisach, W. E. Blumberg, Arch. Biochem. Biophys. 1974, 165, 691708 b)

[38] O. M. Rasia, C. W.. Bertoncini, D. Marsh, W. Hoyer, D. Cherny, M. Zweckstetter, C. Griesinger, T. M. Jovin, C. O. Fernandez Proc. Nat. Acad. Sci. USA, 2005, 102 (12), 1294-4299

[39] R. Pogni, G. Della Lunga, R. Basosi, J. Am. Chem. Soc. 1993, 115, 1546-1550

[40] M. Shukla, K. A. Dorai, Appl Magn Reson. 2012, 43, 485-497.

[41] D. H. Wu, A. D. Chen, C. S. Johnson, Magn. Reson. A. 1995, 115, 260-264.

[42] A. Rockenbauer, L. Korecz, Appl. Magn. Reson. 1996, 10, 29-43.

[43] N. Casañ-Pastor, P. Gomez-Romero, L. C. W. Baker, J. Appl. Phys. 1991, 69, 5088-5091.

[44] O. V. Dolomanov, L. J. Bourhis, R. J. Gildea, J. A. K. Howard, H. Puschmann, Appl. Cryst. 2009, 42, 339-341.

[45] G. M. Sheldrick. Acta Cryst. 2015, A71, 3-8.

[46] F. Neese, Wiley Interdiscip. Rev. Comput. Mol. Sci. 2012, 2, 73-78.

[47] a) J. P.Perdew, Phys. Rev. B 1986, 33, 8822-8824; b) J. P. Perdew, Phys. Rev. B 1986, 34, 7406-7406; c) A. D. Becke, Phys. Rev. A 1988, 38, 3098-3100

[48] F. Neese, J. Comput. Chem. 2003, 24, 1740-1747.

[49] F. Weigend, Phys. Chem. Chem. Phys. 2006, 8, 1057-1065.

[50] D. A. Pantazis, X.-Y. Chen, C. R. Landis, F. Neese, J. Chem. Theory Comput. 2008, 4, 908-919.

[51] D. A. Pantazis, F. Neese, J. Chem. Theory Comput. 2009, 5, 22292238.

[52] a) A. D. Becke, J. Chem. Phys. 1993, 98, 1372-1377; b) C. T. Lee, W.T. Yang, R. G. Parr, Phys. Rev. B 1988, 37, 785-789.

[53] A. Klamt, G. Schürmann, J. Chem. Soc. Perkin Trans. 2 1993, 799-805.

[54] a) M. E. Casida, in Recent Advances in Density Functional Theory, Part I (Ed.: D. P. Chong), World Scientific, Singapore, 1995; b) R. E. Stratmann, G. E. Scuseria, M.J. Frisch, J. Chem. Phys. 1998, 109, $8218-8224$ c) R. Bauernschmitt, R. Ahlrichs, Chem. Phys. Lett. 1996, $256,454-464$

[55] a) S. Hirata, M. Head-Gordon, Chem. Phys. Lett. 1999, 314, 291-299 b) S. Hirata, M. Head-Gordon, Chem. Phys. Lett. 1999, 302, 375-382.

[56] F. Neese, J. Chem. Phys. 2001, 115, 11080-11080.

[57] Chemcraft, http://chemcraftprog.com 


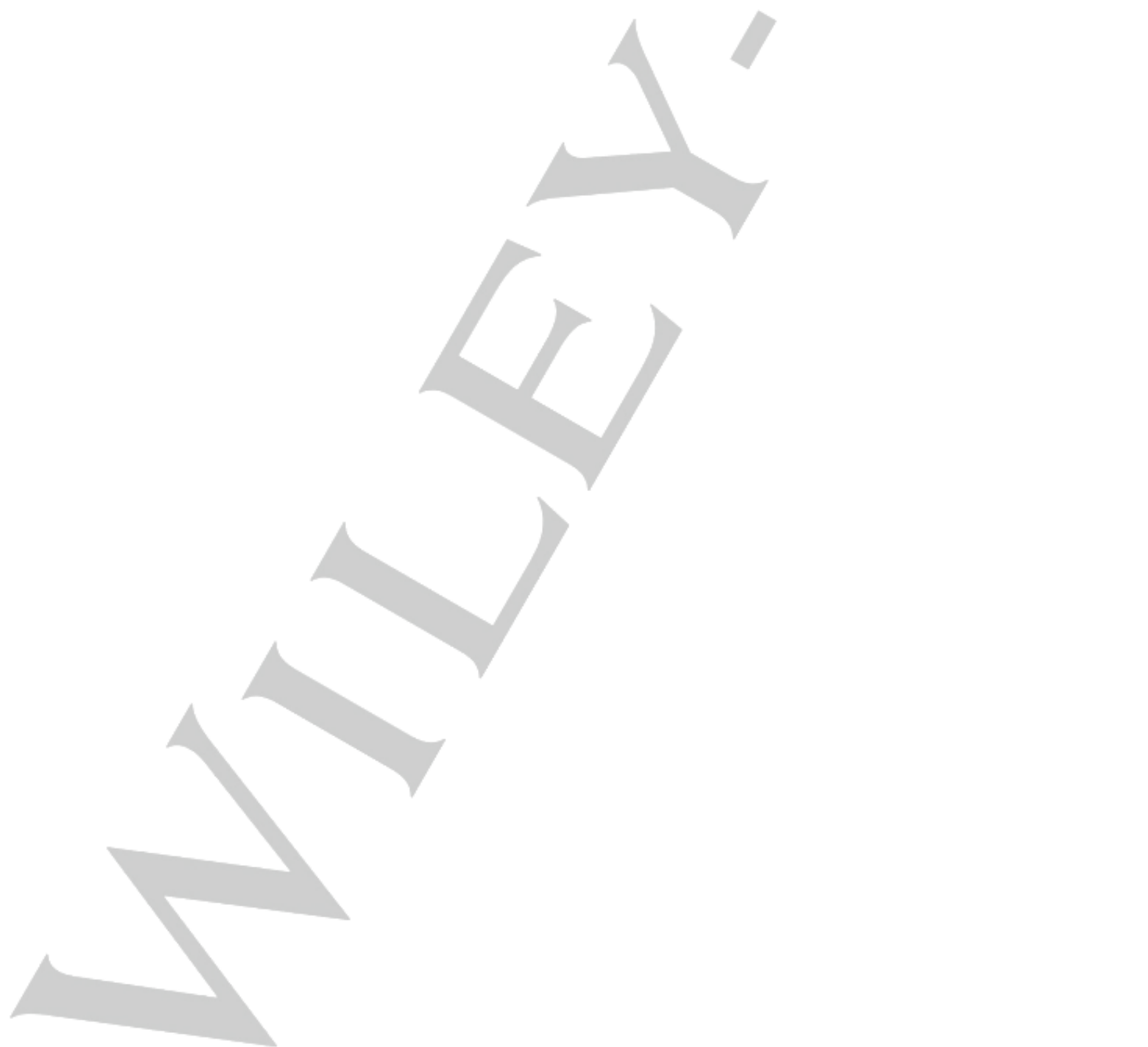

